\title{
DINÁMICAS INSTITUCIONALES EN SITUACIONES DE INNOVACIÓN CURRICULAR: IMPRONTAS DE MITOS FUNDACIONALES
}

Pavan Jorge $\mathrm{V}^{(1,2)}$, Ferreyra Leonardo ${ }_{(3)}^{(1,2)}$ y Nates Siganzoli Patricia ${ }^{(1,2)}$, Mangeaud Arnaldo

(1) Cátedra de Bacteriología y Virología Médicas. Facultad de Ciencias Médicas

(2) Instituto de Virología "Dr JM Vanella". Facultad de Ciencias Médicas

(3) Cátedra de Estadística y Biometría. Facultad de Ciencias Exactas Físicas y Naturales Universidad Nacional de Córdoba

Eje temático 6: Historia de la Universidad. Instituciones, disciplinas y sujetos.

\section{Resumen}

La innovación y el progreso en educación superior parecieran la respuesta a un mundo fluido y cambiante. Sin embargo las innovaciones en las instituciones educativas, tienen una gran complejidad, al considerar que operan sobre los diferentes componentes constitutivos de las mismas. En este trabajo las dinámicas institucionales en situaciones de innovación curricular, encarnadas en las intersubjetividades de un grupo de docentes son analizadas a través de las calificaciones de los exámenes finales de los alumnos las que se pueden interpretar como una manera encubierta de cuestionamiento al proceso de cambio, pero también representan una historia institucional, de mitos fundacionales. Para comprender la complejidad de las instituciones es importante revelar su recorrido histórico y reflexionar sobre el modo en que las prácticas y entretejidos sociales de épocas pasadas se han convertido en estructuras que tanto posibilitan como restringen el presente.

\section{Palabras clave}

Instituciones educativas, innovación curricular, calificaciones alumnos, mitos fundacionales 


\section{Introducción}

A mediados del Siglo XX la Facultad de Medicina de la Universidad Nacional de Córdoba inicia el proceso de profesionalización académica con la llegada de algunos profesores provenientes de universidades europeas para enseñar disciplinas en las que no existían expertos locales. En este período se registran los primeros médicos dedicados plenamente a la enseñanza y a la investigación de diversas disciplinas en el ámbito académico. El inicio de estas trayectorias académicas se caracterizó por una importante pertenencia institucional de los sujetos, a través de una dedicación a tiempo completo así como también a una prolongada permanencia en el tiempo de los sujetos en los puestos académicos (Salord, 2001). Fue así que en el año 1947 la Universidad Nacional de Córdoba contrata al Dr. Georg Karl Wenckebach, originario de Alemania, como Profesor Titular de Microbiología. El Prof Dr Georg Karl Wenckebach (W) inicia una trayectoria académica que duraría 20 años en la Cátedra de Microbiología, de la Facultad de Ciencias Médicas, Universidad Nacional de Córdoba; y puede considerarse que fue quien instituyó y consagró un orden establecido, un estado de las cosas; fue en otras palabras el "fundador" de la Cátedra de Microbiología. El concepto de fundador está relacionado con los actos de institución que lo avalan, significan su identidad frente a los otros, dan cuenta tanto de una investidura como de su autoridad que le permite comunicar lo que es (Bourdieu, 2001: 78). Fundación, identidad, investidura y autoridad envueltos en un movimiento creador que instituye, señalan tanto un corte como un comienzo que consagró al individuo (W) en el primer eslabón de una cadena de intersubjetividades de la que participaron los que por entonces eran profesores de la cátedra (Kaes, 2005:17). Dentro de esta cadena de intersubjetividades se consagró y se sancionó un estado de cosas, se dibujaron los límites de lo pensable y de lo posible, un estilo institucional. En este estilo institucional se consagraron modalidades de distribución del poder, de formas de sistematizar el conocimiento, así como comunicación docente-docente y docente alumno. De este modo lo institucional se vio reflejado en lo curricular; se construyó una propuesta curricular del mítico profesor alemán que significó el modelo oficial de presentación pública del académico (Salord, 2010) con contenidos claramente delimitados y separados entre sí, tipo colección 
(Bernstein, 1977: 75) ${ }^{1}$. La estructura de contenidos específicos estaba organizada desde la taxonomía microbiana, lo que además de mantener el aislamiento se alejaba del enfoque médico. En este modelo oficial estaba presente el temor de los alumnos a los exámenes motivado por la elevada cantidad de aplazos, que daban cuenta de modalidades de enseñanza, propuesta curricular y evaluación, así como de distribución del poder y del control.

Décadas después, cuando $\mathrm{W}$ fallece, aquella cadena de intersubjetividades, fue continuada en sus herederos, un grupo de profesores investidos por las cosas de las que él se había apropiado (Bourdieu, 2008:114). De este modo herederos de aquel estilo e identidad institucional, hicieron propios tanto el estilo como su referente curricular.

Estos herederos llevaron adelante el mito institucional por aquel entonces como "escrito en los pasillos de la cátedra". Por otra parte, los fundadores y herederos transcurren su actividad académica durante períodos históricos de gran complejidad en la Argentina: las dictaduras militares. De la mano de estas estructuras de gobierno y poder, algunos docentes provenían de este ámbito o bien mantenían relaciones muy estrechas con las fuerzas armadas o el clero.

En la dinámica de lo institucional (Fernández, 2001:36) como dimensiones complementarias, lo instituido (lo fijo, lo estable) se alterna con lo instituyente (el cuestionamiento, la crítica, la propuesta opuesta, la transformación). Con la llegada de la democracia, algunos nuevos académicos proponen intentos de cambio, sin lograr avanzar en su cometido. En el año 1996, con la llegada de un nuevo académico como profesor titular se pone en marcha un cambio cualitativo a la situación preexistente. Este cambio curricular introdujo una discontinuidad metodológica, pues significó para alumnos y algunos docentes, "los innovadores", apropiarse de una mirada diferente (Yentel, 2011). Esta mirada correspondió a actividades que implicaron por una parte, una participación activa de los estudiantes en sus procesos de aprendizaje y por otra, facilitar el alcance de niveles de comprensión más complejos y profundos en los que el conocimiento adquirido fuera construido en una estructura interna flexible. Para ello se eligió la estrategia didáctica de taller con aprendizaje basado en problemas y estudio de

\footnotetext{
${ }^{1}$ Bernstein (1977) diferencia dos tipos de curriculum: (i) tipo colección, si los contenidos están claramente delimitados, separados entre sí, y mantienen una relación cerrada (ii) tipo integrado, si los contenidos mantienen entre sí una relación abierta, con contenidos transversales. En el curriculum tipo colección el conocimiento "implica una jerarquía en la que el último misterio de la asignatura se revela muy tardíamente en la vida educativa. Y la educación adopta una larga iniciación en el misterio. El conocimiento entra en el terreno de lo sagrado. No es ni ordinario ni mundano. Y esto realza la significación de la asignatura para quienes la profesan. Es una forma muy poderosa de control" (pp 77)
} 
casos. Se diseñaron ámbitos de participación y discusión del nuevo diseño curricular en la que los objetivos estaban dirigidos hacia un desarrollo de determinadas competencias para el futuro médico. El contenido curricular fue modificado luego de dos años, para el logro de habilidades y competencias médicas así como se diseñaron organizadores transversales, que permitieron al alumno una mirada completa de la asignatura desde su inicio. Los contenidos mantenían entre sí una estructura abierta de tipo integrado y relacional (Bernstein, 1977: 82) ${ }^{2}$. La propuesta de cambio implementada en dicho establecimiento articuló decisiones respecto a los modos de evaluación y acreditación de los estudiantes. De este modo el cambio curricular adecuaba una nueva estructura que tenía una importante diferencia con la anterior (Abdala, 2007), en cuanto conceptualizaba diferentes modelos de autoridad y de control.

En este cambio de identidad educativa era importante debilitar la larga socialización previa en la "lealtad a una asignatura" (Bernstein, 1977: 90) y otorgar una identidad distinta a la trama curricular. Fue así que la asignatura cambió de nombre y pasó a llamarse Bacteriología y Virología Médicas. Los aspectos señalados, entre otros, dan cuenta que se trató de una experiencia innovadora en la Facultad de Ciencias Médicas de la Universidad Nacional de Córdoba.

Sin embargo, cualquier intento de cambiar la estructura curricular, de cambio de los criterios de clasificación es considerado una amenaza y genera una fuerte resistencia. Los docentes que participaron del cambio conformaron un grupo innovador que de la mano de una nueva propuesta curricular y con el apoyo del profesor titular de la cátedra, encarnó lo instituyente. Herederos e innovadores, conformaron grupos en tensión que más allá de la nueva propuesta mostraban miradas diferentes en relación a la enseñanza y la evaluación, que se entrelazaron con los mitos fundacionales de la cátedra. El proceso de cambio modificó el orden establecido y representó para determinados sujetos una vivencia de crisis entendida como ruptura intersubjetiva (Kaes, 2005: 32), que pudo tener implicancias en la práctica docente y en las exigencias académicas hacia los estudiantes desarrolladas en las situaciones de evaluación del alumno en los exámenes finales.

\footnotetext{
${ }^{2}$ Bernstein refiere que en el curriculum integrado se altera la estructura del poder tradicional en las instituciones educativas: "los profesores de las diferentes asignaturas entablarán relaciones entre sí que provendrán no sólo de sus actividades de ocio, sino de una tarea educativa cooperativa y compartida. De este modo en lugar de que los profesores y los conferenciantes estén divididos y aislados por lealtades jerárquicas a una asignatura, estarán unidos por una tarea común”. (pág 79).
} 
La Institución Universitaria en Argentina dicta las exigencias académicas de los estudiantes (Ley de Educación Superior No 24.521, año 1995) y además los exámenes y las evaluaciones que establecen el régimen de acceso, permanencia y promoción así como los grados académicos y títulos habilitantes. Esto adquiere particular importancia cuando se trata de títulos correspondientes a profesiones reguladas por el Estado, cuyo ejercicio pudiera comprometer el interés público poniendo en riesgo de modo directo la salud; tal es la situación de esta cátedra en la Facultad de Ciencias Médicas.

En este marco ¿Es posible entonces que las exigencias académicas hacia los alumnos sean utilizadas como manera encubierta de aprobación o cuestionamiento al proceso de cambio? Es en este sentido que Bernstein (1977: 77) refiere "El curriculum, la pedagogía y la evaluación deben ser considerados como un todo. El modo en que la organización, la transmisión y la evaluación selectivas del conocimiento están íntimamente ligadas a modelos de autoridad y control"

El objetivo del trabajo es desde una perspectiva institucional empírica analizar la incidencia y su efecto en las exigencias académicas hacia los alumnos que puede tener la pertenencia del docente a un subgrupo en competencia o pacto con otros como manera encubierta de aprobación o cuestionamiento al proceso de cambio.

El trabajo intenta desde el análisis de un aspecto o franja que considera las calificaciones en los exámenes finales como un elemento dentro de todo un lenguaje de acontecimientos involucrados en la respuesta a un cambio.

\section{Las calificaciones de los alumnos como un relato institucional}

Para ello fueron analizadas las calificaciones de los exámenes finales de los alumnos de la Cátedra de Bacteriología y Virología Médicas de la Universidad Nacional de Córdoba. Fueron analizadas $n=5278$ calificaciones que correspondieron: (a) calificaciones durante el período W (años1961-1969, $n=3988$ ) y (b) calificaciones de los alumnos aprobados (en el turno de examen del mes de marzo) desde 1999 a 2005 $(n=1290)$, que fueron categorizadas por la pertenencia del docente como (i)Innovadores $(n=866)$, (ii) Herederos $(n=425)$. Con el fin de observar si se presentaban diferencias significativas entre los medias de las calificaciones por Grupo Docente, se realizó el test $t$ para diferencias de medias entre los grupos, las diferencias de medias entre los grupos durante los años fueron estudiados con análisis de la 
varianza. Se realizaron comparaciones "a posteriori "con la Prueba LSD de Fisher. Se graficaron las distribuciones de calificaciones de cada grupo. Se aceptó como nivel de significación un $\alpha$ del 5\%.

La media de las calificaciones del grupo innovadores fue 7,32 mientras que la media en el grupo herederos fue 6,15. Las diferencias de las calificaciones entres los grupos fueron estadísticamente significativas (test $t$ Student, $\mathrm{p}<0,0001$ ).

En las Figura 1 se observa la distribución de las frecuencias relativas de las calificaciones colocadas por el Grupo Herederos desde el año 1999 al 2005 y en la Figura 2 la distribución de frecuencias de las calificaciones colocadas por el Grupo Innovadores en el mismo período.

En la Figura 3 se observa la variación temporal (desde el año 1999 al año 2005) de las calificaciones, discriminadas por Grupo Docente. Allí se presenta una clara diferencia entre los grupos, lo que se corrobora con el análisis de la varianza, que demostró que estas diferencias fueron significativas (Prueba LSD de Fisher; $p<0,001$ ). También se observan diferencias entre años $(\mathrm{p}=0,026)$.

Figura 1. Distribución de frecuencias de las calificaciones colocadas por el Grupo Herederos desde el año 1999 al 2005

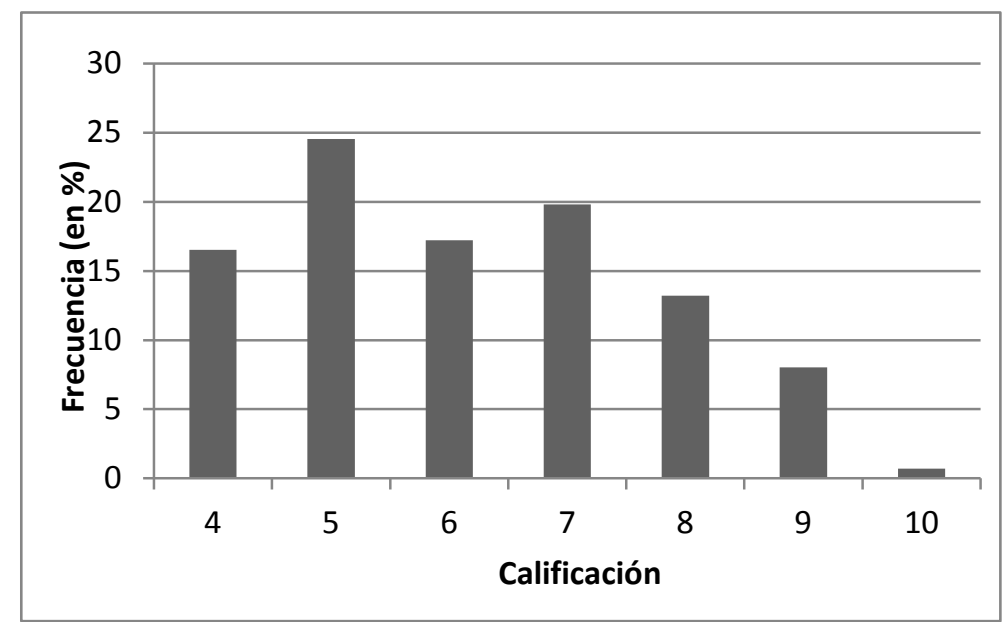


Figura 2 Distribución de frecuencias de las calificaciones colocadas por el Grupo Innovadores desde desde el año 1999 al 2005

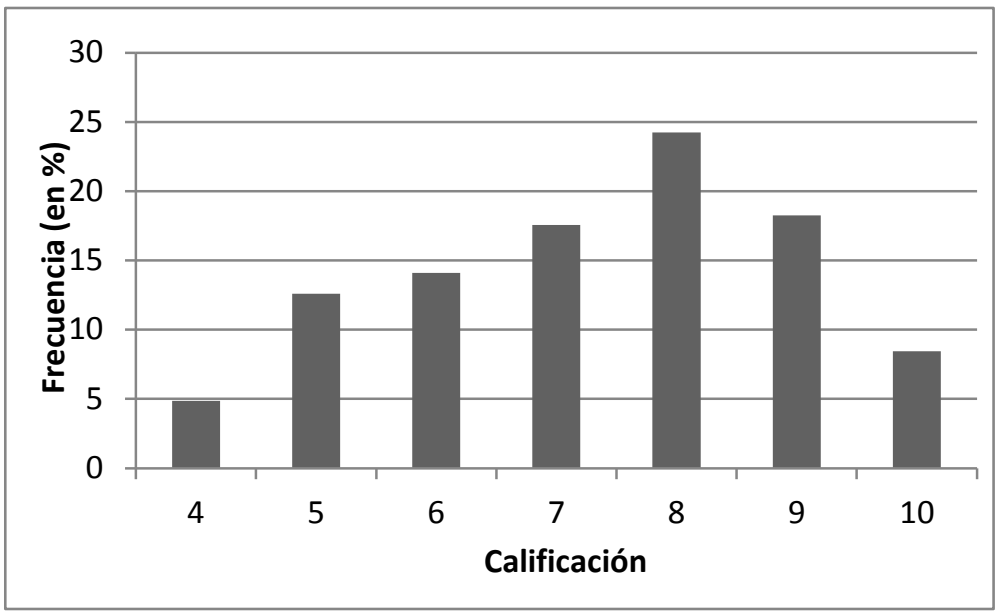

Figura 3: Variación de las notas de los alumnos, discriminada por Grupo docente

(Grupo Innovadores y Herederos), a lo largo de 1999 a 2005. Se consigna el promedio por año con su correspondiente Error Estándar.

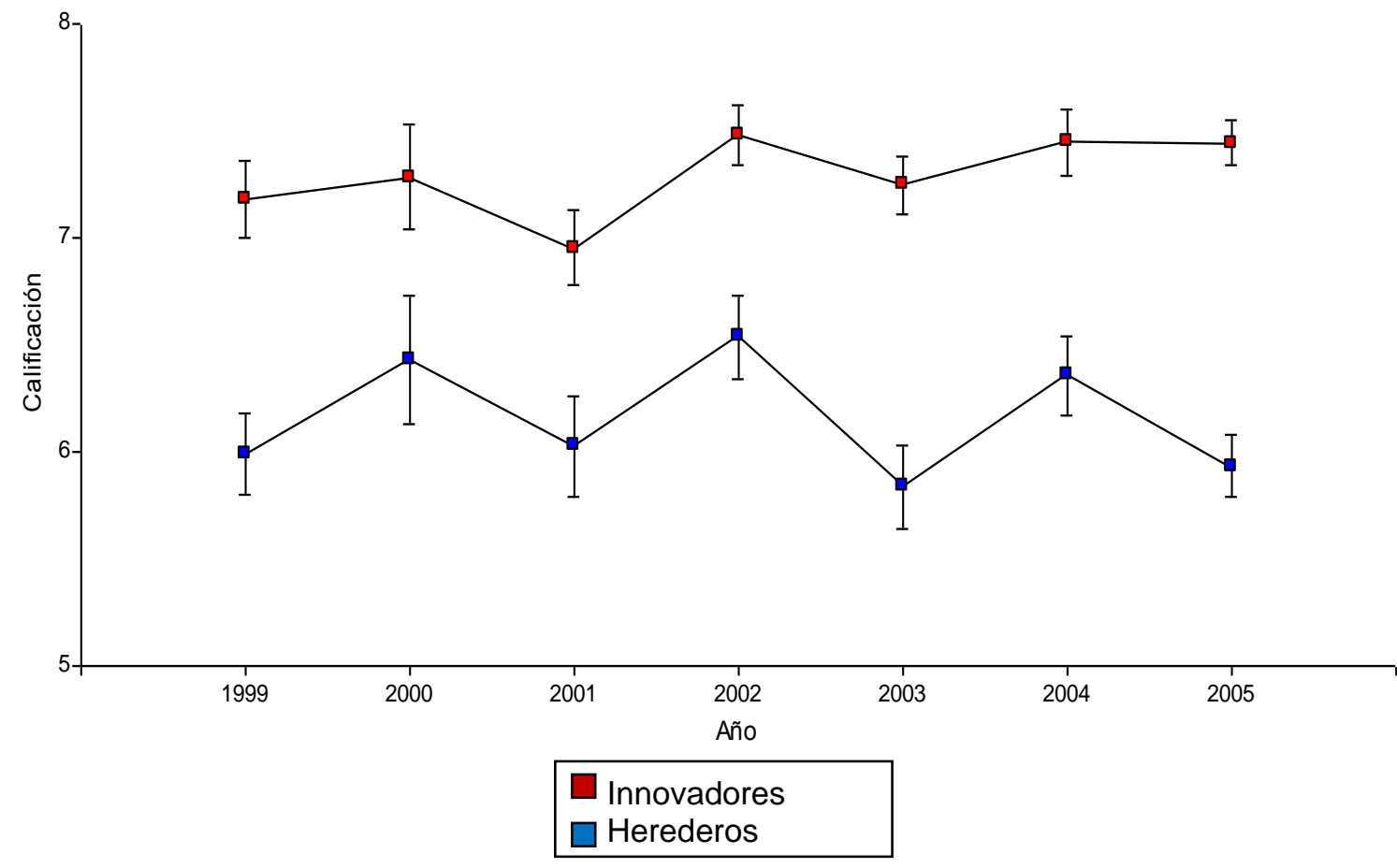




\section{Improntas de los mitos fundacionales}

Con la finalidad de establecer relaciones entre las calificaciones que el grupo de Herederos utilizó para aprobar a los alumnos, con las calificaciones que (W) utilizó para aprobar a los alumnos, se realizó un análisis de regresión. Para el tratamiento de los datos, el $n$ de las frecuencias absolutas que correspondieron a cada una de las calificaciones $(4,5,6,7,8,9$ y 10$)$ fueron transformadas en $\log _{10}$ para obtener una distribución normal. Se analizaron luego los coeficientes de regresión y los estadísticos asociados.

En la Figura 4 se observa el análisis de regresión entre las calificaciones (W) y las del Grupo Herederos. El análisis de regresión demostró una relación lineal de tendencia positiva entre las frecuencias absolutas de las calificaciones de Wenckebach y las frecuencias absolutas de las calificaciones de Herederos: $\mathrm{r}^{2}=0,76, p<0,01$, cuya función lineal fue $(y) \log _{10}$ calificación herederos $=-1,65+1,32(x) \log _{10}$ calificaciones W. Así también se ha graficado el 95\% del Intervalo de Confianza en la recta de regresión.

Figura 4. En la figura se observa una relación lineal $(p=0,01)$ entre las calificaciones de W y las de Herederos (r2=0,72) así como también las bandas con el 95\% de Intervalo de Confianza

\section{Regresion lineal y bandas de confianza}

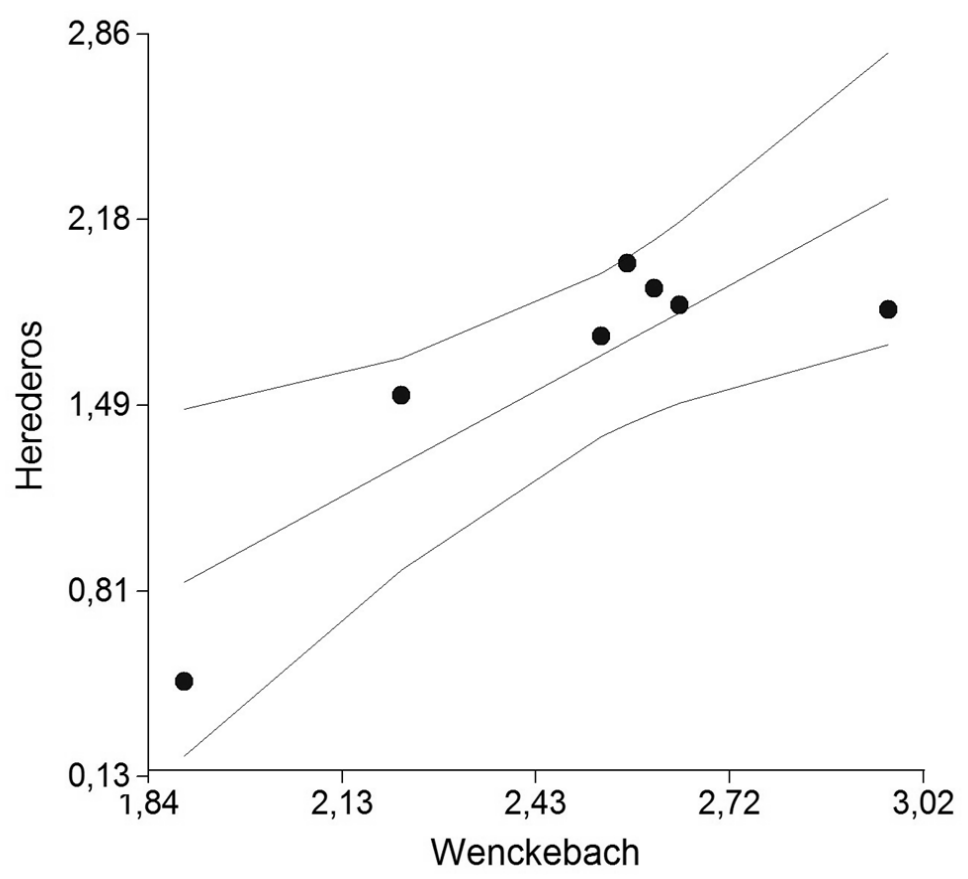




\section{La memoria institucional}

Las cátedras son instituciones en donde las diferentes tareas educativas relacionadas a ayuda e intercambio afectivo, control, vida institucional competitiva, poder y conocimiento se entrelazan y activan distintos componentes simbólicos como ejercicio de poder, temor a la exclusión y al castigo, entre otros (Fernandez, 2001: 25). Pensar la institución, hacer de ella objeto de análisis tiene dificultades, en parte porque "nos piensa y nos habla" (Kaes et al,2000: 16) más aún:

"la institución nos precede, nos sitúa en sus vínculos y sus discursos".

Pensar una institución es analizar la dinámica institucional en términos de una mirada que intenta dar cuenta de su funcionamiento en un tiempo determinado (Butelman et al:: 16). El término "dinámica" resulta apropiado para este trabajo, pues en su lógica subyace un modelo basado en el movimiento y en la contradicción. Contradicción pues en su funcionamiento es posible encontrar tanto modalidades acompañadas de prejuicio, circulación fantasmática (Malfe, 1995) y aislamiento progresivo como así también modalidades en donde predomina el control y la discriminación de los aspectos irracionales, autonomía respecto de las instituciones externas y posibilidad de ensayar modificaciones de lo instituido, con intenso compromiso y una clara orientación hacia el futuro $^{3}$. (Fernandez, 2001: 58).

De este modo es en la dinámica de estas instituciones en donde diferentes grupos que configuran redes sociales con distintas concepciones de la autoridad y del control; los que pueden ante el temor, la amenaza o bien la confrontación por situaciones de cambio, encontrar dentro de los espacios educativos elementos que permitan articular su disconformidad. Uno de los espacios educativos es la tarea de evaluación que además de reflejar la distribución del poder y los principios del control social (Bernstein, 2001), es utilizada como una manera encubierta de aprobación o cuestionamiento al proceso de cambio (Fernández, 2001: 37).

En esta experiencia la pertenencia a los docentes a distintos grupos (Innovadores y Herederos) se vio reflejada en las calificaciones de los exámenes finales de los alumnos.

\footnotetext{
${ }^{3}$ Fernandez (2001) describe como recurso metodológico la posibilidad de hablar de (i) modalidades regresivas, determinadas por la pérdida de la capacidad institucional para evaluar situaciones, discriminar necesidades y problemas, y originar líneas exploratorias de solución, (ii) modalidades progresivas acompañada por el control de los procesos irracionales, la posibilidad de modificar lo instituido con disponibilidad hacia la curiosidad, el interés y la exploración.
} 
Los docentes del Grupo Innovador evaluaron en los exámenes finales con puntuaciones más altas que las del Grupo Herederos ( $p<0,0001$ ), si consideramos las medias. Además esta característica de calificación por parte de ambos grupos permaneció en el tiempo, durante al menos 7 años (Figura 3). De esta manera estas calificaciones son un reflejo del relato institucional, de los acontecimientos que sucedieron en la institución, de los docentes en relación a la institución y en relación a su percepción sobre el conocimiento considerado como válido al momento de la evaluación. El mecanismo de evaluación involucra procesos sociales de distinción y existen relaciones entre los juicios de los maestros y las divisiones objetivas del mundo social (Bourdieu, 2006:124).

Lo que es más, en este trabajo se refleja que la disconformidad y los conflictos que se generan en torno a los cambios institucionales se entrelazan a menudo con los patrones heredados con los que funciona la dinámica pedagógica, en palabras de Kaes (2002:17) "el fantasma de la escena originaria". Este "fantasma de la escena originaria" se refleja en la Figura 4 en donde se observa el análisis de regresión entre las calificaciones (W) y las del Grupo Herederos, el que demuestra una relación lineal positiva entras las calificaciones de ambos grupos. Es decir que las calificaciones del Grupo Herederos no sólo se pueden interpretar como manera encubierta de cuestionamiento al proceso de cambio, sino que también representaban una historia institucional, de un mito fundacional encarnado en las intersubjetividades de un grupo. Lo que es más, Kaes (2002:47) rescata una mayor complejidad en el heredero cuando refiere que el sujeto de la herencia está dividido entre la doble necesidad de ser para sí mismo su propio fin y de ser el eslabón de una cadena a la que está sujeto sin la participación de su voluntad pero a la que debe servir y de la que puede esperar un beneficio. En este sentido no hemos encontrado publicaciones científicas con las cuales contrastar estos hallazgos de dinámicas institucionales en educación superior reflejadas en las calificaciones de los exámenes finales. La personalidad del Dr. Wenckebach sumado a la continuidad en su permanencia, han signado una imagen y un estilo que ha permanecido en el tiempo (Enriquez, 2002). Muchos años después de su desaparición pueden escucharse en los pasillos y en las aulas las improntas de su particular gestión que acuñó un estilo institucional en un grupo de docentes que se transformaron en sus herederos.

La innovación y el progreso en educación superior parecieran la respuesta a un mundo fluido y cambiante. Sin embargo las innovaciones en las instituciones educativas, tienen 
una gran complejidad, al considerar que operan sobre los diferentes componentes constitutivos de las mismas.

Para comprender la complejidad de estas instituciones es importante revelar su recorrido histórico y reflexionar sobre el modo en que las prácticas y entretejidos sociales de épocas pasadas se han convertido en estructuras que tanto posibilitan como restringen el presente. Las instituciones operan como reservorios sociales de recuerdos individuales y comunes que conforman una memoria institucional (Corvalán de Mezzano, 1998). En esta memoria, las condiciones de espacio, tiempo, personas, fines, propuestas curriculares son componentes constitutivos en donde (Fernández, 2001) los sujetos perciben al mundo institucional instituido como el único posible.

\section{Bibliografía}

ABDALA, Carolina (2007), Curriculum y enseñanza: claroscuros de la formación universitaria, Córdoba, Brujas.

BERNSTEIN, Basil (1977), Clases, códigos y control: Hacia una teoría de las transmisiones educativas, Madrid, Akal.

BERNSTEIN, Basil (2001), La estructura del discurso pedagógico, Madrid, Morata.

BOURDIEU, Pierre (2001), ¿Qué significa hablar?, Madrid, Akal, pp 78-95.

BOURDIEU, Pierre (2006), La distinción. Criterios y bases sociales del gusto, Buenos Aires, Taurus.

BOURDIEU, Pierre (2008), Homo academicus, Siglo veintiuno Editores, Buenos Aires Argentina, pp 114-121.

BUTELMAN, Ida, CORVALÁN DE MEZZANO, Alicia, SOUTO, Marta, GARAY Lucía, FERNÁNDEZ, Lidia (1998), Pensando las instituciones, Buenos Aires, Paidós.

CORVALÁN DE MEZZANO, ALICIA (1998). "Recuerdos personales-memorias institucionales: hacia una metodología de la indagación histórico-institucional”, en I. 
Butelman (compiladora). Pensando las instituciones. Sobre teorías y prácticas en educación, Buenos Aires, Paidós.

ENRIQUEZ, Eugène (1989). "El trabajo de la muerte en las instituciones”, en Kaës (coord.). La institución y las instituciones, Buenos Aires, Paidós.

FERNÁNDEZ, Lidia M (2001), Instituciones educativas, Buenos Aires, Paidós.

KAËS, René (2000), Las teorías psicoanalíticas del grupo, Buenos Aires, Amorrortu.

KAËS, René, BLEGER José, ENRIQUEZ, Eugène, FORNARI, Franco, FUSTIER, Paul, ROUSILLON, René, VIDAL, Jean-Pierre (2002). La institución y las instituciones, Buenos Aires, Paidós.

KAÉS,René (2005), Sufrimiento y psicopatología de los vínculos institucionales, Buenos Aires, Paidós.

MALFE, Ricardo (1995), Fantásmata, Buenos Aires, Amorrortu.

SALORD, García Susana (2001), “ Las trayectorias académicas: de la diversidad a la heterogeneidad", Revista Mexicana de Investigación Educativa, núm 11, México, pp. $15-31$.

SALORD, García Susana (2010), “El curriculum vitae: entre perfiles deseados y trayectorias negadas", Revista Iberoamericana de Educación Superior (RIES), núm 1, México, pp. 103-119.

YENTEL, Nora (2011), “Aportes para el análisis de un proyecto de cambio educativo”, Praxis Educativa, núm 14, Universidad Nacional de La Pampa, La Pampa, Argentina, pp. 85-93.

Otras fuentes

Ley Nacional de Educación Superior 24521. Acceso diciembre 2012 en http://www.fadu.uba.ar/institucional/leg_index_sup.pdf 